\title{
Proliferative Enteropathy (PE)-Induced Changes in the Calbindin-Immunoreactive (CB-IR) Neurons of Inferior Mesenteric Ganglion Supplying the Descending Colon in the Pig
}

\author{
Joanna Wojtkiewicz • Maciej Równiak • \\ Slawomir Gonkowski • Robert Crayton • \\ Mariusz Majewski • Anna Robak • Joanna Białkowska • \\ Monika Barczewska
}

Received: 15 October 2011 / Accepted: 2 December 2011 / Published online: 15 December 2011

(C) The Author(s) 2011. This article is published with open access at Springerlink.com

\begin{abstract}
A subpopulation of the pig inferior mesenteric ganglia (IMG) neurons projecting to the colon exhibit calbindin-like immunoreactivity. It is not known if there are any changes in the chemical coding patterns of these neurons during porcine proliferative enteropathy (PE). To answer this question, juvenile Large White Polish pigs with clinically diagnosed Lawsonia intracellularis infection (PE; $n=3)$ and a group of uninfected controls $(\mathrm{C} ; n=3)$ were
\end{abstract}

J. Wojtkiewicz $(\bowtie) \cdot J$. Białkowska $\cdot$ M. Barczewska

Department of Neurology and Neurosurgery,

Division of Neurosurgery, Faculty of Medical Sciences,

University of Warmia and Mazury in Olsztyn,

Warszawska 30,

10-082 Olsztyn, Poland

e-mail: Joanna.Wojtkiewicz@uwm.edu.pl

M. Równiak · A. Robak

Department of Comparative Anatomy, Faculty of Biology, University of Warmia and Mazury in Olsztyn,

Olsztyn, Poland

S. Gonkowski

Department of Clinical Physiology,

Faculty of Veterinary Medicine,

University of Warmia and Mazury in Olsztyn,

Olsztyn, Poland

\section{R. Crayton}

Department of General, Oncological and Functional Urology,

Medical University of Warsaw,

Warsaw, Poland

M. Majewski

Department of Human Physiology,

University of Warmia and Mazury in Olsztyn,

Olsztyn, Poland compared. The retrograde tracer fast blue (FB) was injected into the descending colons of all animals and then tissue comprising IMGs from both groups was processed for double-labeling immunofluorescence with calbindin-D28k (CB) in combination with either tyrosine hydroxylase (TH), neuropeptide Y (NPY), somatostatin (SOM), vasoactive intestinal polypeptide (VIP), nitric oxide synthase, Leuenkephalin, substance $\mathrm{P}$, vesicular acetylcholine transporter, galanin, or pituitary adenylate cyclase-activating polypeptide. Immunohistochemistry revealed changes in the chemical coding pattern of calbindin-immunoreactive neurons in the inferior mesenteric ganglia of the pig. In control animals, FB/CB-positive neurons were immunoreactive to TH, NPY, SOM, and VIP. In the experimental group, TH-expressing neurons were unaffected, NPY-expressing neurons were increased, whereas the number of neurons immunoreactive to SOM or VIP was reduced. Changes in chemical coding of $\mathrm{CB}$ neurons during PE may play an important role in adaptation of these IMG cells under pathological conditions.

Keywords Porcine proliferative enteropathy.

Neuropeptides · Colon supplying neuron · Inferior mesenteric ganglion $\cdot$ Pig

\section{Introduction}

It is well known that the gastrointestinal (GI) tract is unique with respect to the arrangement of its innervation. The regulation of the stomach and gut is controlled by the enteric nervous system (ENS) which is distributed in the intramural 
ganglia (Brown and Timmermans 2004). The ENS is capable of acting almost independently from other parts of the nervous system, but some functions of GI tract are also regulated by extrinsic autonomic innervation. Autonomic neurons supplying the stomach and gut are localized within the prevertebral or paravertebral ganglia and are involved in the regulation of motility, secretion, and blood flow within the organs mentioned above (Brown and Timmermans 2004; Furness 2000; Luckensmeyer and Keast 1994). Previous investigations have shown that the main source of colon autonomic innervation originates from the inferior mesenteric ganglion (IMG) (Dalsgaard and Elfvin 1982; Li and Masuko 1997; Pidsudko et al. 2001; Wojtkiewicz et al. 2011). These IMG neurons supplying the GI tract colocalize several neurotransmitters and/or neuromodulators (Li and Masuko 1997; Pidsudko et al. 2001; Trudrung et al. 1994; Wojtkiewicz et al. 2011).

The neuropeptide calbindin (CB) was first identified in the intestines of the chicken (Wasserman et al. 1966) and later studies have identified CB within intramural and extrinsic enteric neurons ( $\mathrm{Li}$ and Masuko 1997, 2001; Resibois et al. 1988; Wojtkiewicz et al. 2011). However, the role of $\mathrm{CB}$ in the GI tract has not yet been fully elucidated. CB belongs to a family of calcium-binding proteins and is thought to play a major role in buffering intracellular $\mathrm{Ca}^{2+}$ and various $\mathrm{Ca}^{2+}$-mediated signaling pathways (Cho et al. 2011). Neuronal calcium could have a significant role in neuronal survival as well as programmed cell death and pathological neuronal damage but this remains controversial. Neurons rich in CB seem to be relativity resistant to damage or degeneration in a variety of acute and chronic diseases (Bastianelli 2003). Previous studies on CB immunoreactivity in the ENS advocate that calbindin co-localizes with many neurochemical substances and could be used as an identifying marker for a specialized subpopulation of neurons within the ENS (Brown and Timmermans 2004; Furness 2000). It is also known that both intramural neurons of the ENS and the autonomic extrinsic neurons innervating the GI tract are able to change their structural, functional, or chemical phenotype as an adaptive response to various physiological and pathological stimuli, such as a diet, ontogenesis, or intestinal and extraintestinal diseases (Balemba et al. 1998; Ekblad 1999; Gonkowski and Calka 2010; Lakomy et al. 2005; Phillips and Powley 2007; Pidsudko et al. 2008; Vasina et al. 2006). Contrary to intramural enteric neurons, there is a paucity of data regarding the plasticity of autonomic extrinsic neurons supplying the GI tract, especially in the porcine animal model (Lakomy et al. 2005; Wojtkiewicz et al. 2011). The structure and distribution of the porcine enteric neurons closely resemble those of the human in respect of anatomical, physiological, and pathological characteristics (Brown and Timmermans 2004). Moreover, most of the data on the ENS and extrinsic innervation plasticity in pathological states have been acquired using experimental models, where different agents have been applied into the lumen of the gut or injected into the colon wall (for review, see Biasi et al. 2011; Elson et al. 1995). However, the data concerning neurochemical changes in the ENS during "natural" inflammation associated with diseases affecting the alimentary system are rather limited (Pidsudko et al. 2008).

Proliferative entheropathy (PE) is an intestinal disease that can induce significant changes in the chemical coding of intramural enteric neurons (Pidsudko et al. 2008). Although the disease was originally described in 1931 (McOrist and Lawson 1993), its ethological agent — the intracellular bacterium Lawsonia intracellularis was only identified in the 1990s (Lawson et al. 1993). Contrary to other inflammatory diseases of the alimentary tract, $\mathrm{PE}$ is characterized by proliferative changes, such as hyperplasia of immature epithelial cells in different parts of intestinal tract, most frequently within the ileum and colon (Lawson and Gebhart 2000; Smith and Lawson 2001). Moreover, this disease is characterized by epithelial cell degeneration, necrosis, and sometimes ulceration or hemorrhage (Lawson and Gebhart 2000). Until now, the available data regarding the influence of $\mathrm{PE}$ on the immunoreactivity of extrinsic enteric neurons are lacking and few studies have addressed this issue (Wojtkiewicz et al. 2004).

The aim of this study was to identify the number and neurochemical characterization of CB-containing neurons of IMG supplying the porcine descending colon and to further analyze their plastic capacity during proliferative enteropathy.

\section{Material and Methods}

Animals The study was performed on six immature female pigs of the Large White Polish breed (approximately 8 weeks old) divided into two groups: control animals (C group; $n=3$ ) and animals with clinically diagnosed $L$. intracellularis infection (PE group; $n=3$ ). The animals of the PE contracted the $L$. intracellularis infection by housing them in a herd, in which the infection has previously been detected and characterized chronically. Thus, as described below, six animals were retrogradely traced and then housed together with animals recently diagnosed with chronic PE. After 2 weeks, the animals were examined by a veterinary surgeon, and subjects with suspected PE were entered into the experimental group. The diagnosis of PE was then confirmed by post-mortem using a polymerase chain reaction-based test performed at the State Veterinary Research Institute in Pulawy (Poland). All animals were housed and treated in accordance with the Principles of Laboratory Animal Care, NIH publication no. 86-23, revised 1985. The surgical and experimental procedures were approved by the Ethics Committee in Olsztyn (Poland). 
Anesthesia and Surgery Surgery was performed under fractionated thiobarbital (Thiopenthal, Sandoz, Austria; $20 \mathrm{mg} / \mathrm{kg}$ b.w., i.v.) anesthesia. Prior to administration ( $30 \mathrm{~min}$ ) of the main anesthetic, the animals were pretreated with atropine sulphate (Polfa, Poland; $0.04 \mathrm{mg} / \mathrm{kg}$ b.w., s.c.) and azaperone (Stressnil, Janssen Pharmaceutica, Belgium; $2.0 \mathrm{mg} / \mathrm{kg}$ b.w., i.m.). All animals $(n=6)$ were laparotomized and injected with $5 \%$ aqueous solution of the fluorescence retrograde neuronal tracer fast blue (FB; Dr. K. Illing GmbH, GrossUmstadt, Germany) into wall of the descending colon. A total volume of $40 \mu \mathrm{l}$ of $5 \%$ aqueous dye solution was injected into the exposed descending colon using a Hamilton syringe with a 26-gauge needle. Multiple ( $n=40 ; 1 \mu$ leach) injections were made into the right part of descending colon. After 3 weeks, all animals (C and PE) were re-anesthetized as described above and euthanized by overdosage of thiobarbital and transcardially perfused with $4 \%$ buffered paraformaldehyde ( $\mathrm{pH}$ 7.4). Following the perfusion, small tissue blocks comprising the IMG were collected from all studied animals, postfixed by immersion in the same fixative for $4 \mathrm{~h}$, washed twice in $0.1 \mathrm{M}$ phosphate buffer $\left(\mathrm{pH}=7.4,4^{\circ} \mathrm{C}\right)$ and then stored in $18 \%$ sucrose at $4^{\circ} \mathrm{C}$ until sectioning.

Immunofluorescence Experiments Ten-micrometer thick cryostat sections of IMGs were processed for routine double-immunofluorescence labeling using primary antisera raised in different species and species-specific secondary antibodies (Table. 1). Briefly, all sections were incubated in humid chambers with a mixture of two primary antisera raised in different species (overnight). The mixture consisted of antibodies directed towards calbindin-D28k (CB) and antisera raised against tyrosine hydroxylase $(\mathrm{TH})$ or neuropeptide Y (NPY) or somatostatin (SOM) or vasoactive intestinal polypeptide (VIP) or nitric oxide synthase (NOS) or leu(5)-enkephalin (LENK) or substance P (SP) or vesicular acetylcholine transporter (VAChT) or galanin (GAL), or pituitary adenylate cyclase-activating polypeptide (PACAP) (Table. 1). Then sections were incubated with a mixture of FITC-conjugated secondary antisera and biotin $(1 \mathrm{~h})$. The latter antibodies were visualized by additional incubation of the sections with streptavidin-CY3 complex $(1 \mathrm{~h})$. After staining, the sections were mounted with carbonatebuffered glycerol $(\mathrm{pH}$ 8.6) and applied with cover slips. Each step of the immunolabeling was followed by rinsing with PBS $(3 \times 15 \mathrm{~min})$.

Controls Standard controls, i.e., preabsorption for the neuropeptide antisera (20 $\mathrm{mg}$ of appropriate antigen per $1 \mathrm{ml}$ of corresponding antibody at working dilution), and the omission and replacement of all primary antisera by non-immune sera or PBS were applied to test both antibody- and method specificity.

Counting and Statistics The sections were viewed under an Olympus BX51 fluorescence microscope equipped with a barrier filter for FB. Images were acquired by a PC equipped
Table 1 Specification of immunoreagents

\begin{tabular}{lllll}
\hline Antigen & Code & Host species & Dilution & Supplier \\
\hline $\begin{array}{l}\text { Primary antibodies } \\
\text { CB }\end{array}$ & CB-38 & & \\
TH & MAB 318 & Rabbit & $1: 20,000$ & SWANT \\
NPY & NZ1115 & Mouse & $1: 80$ & Chemicon \\
SOM & Rat & $1: 300$ & Biomol \\
VIP & 8330-0009 & Rat & $1: 100$ & Biogenesis \\
NOS & $9535-0504$ & Mouse & $1: 2,000$ & Biogenesis \\
LENK & N2280 & Mouse & $1: 2,000$ & Sigma \\
SP & 4140-0355 & Mouse & $1: 1,000$ & Biogenesis \\
VAChT & R450-0505 & Gat & $1: 300$ & Biogenesis \\
GAL & H-V007 & Guinea Pig & $1: 2,000$ & Phoenix \\
PACAP & T-5036 & Guinea Pig & $1: 1,000$ & Peninsula \\
Secondary reagents & T-5039 & & $1: 1,000$ & Peninsula \\
Donkey anti-mouse IgG (H+L) conjugated with FITC & & \\
Donkey anti-rat IgG (H+L) conjugated with FITC & & $1: 800$ & Jackson \\
Donkey anti-guinea pig IgG (H+L) conjugated with FITC & $1: 800$ & Jackson \\
Donkey anti-goat IgG (H+L) conjugated with FITC & $1: 1,000$ & Jackson \\
Biotinylated goat anti-rabbit immunoglobulins & $1: 1,000$ & Jackson \\
Biotin conjugated F(ab) & fragment of affinity purified anti-rabbit IgG (H+L) & $1: 1,000$ & BioTrend \\
CY3-conjugated Streptavidin & & $1: 9,000$ & Jackson \\
\hline & & & \\
\hline
\end{tabular}




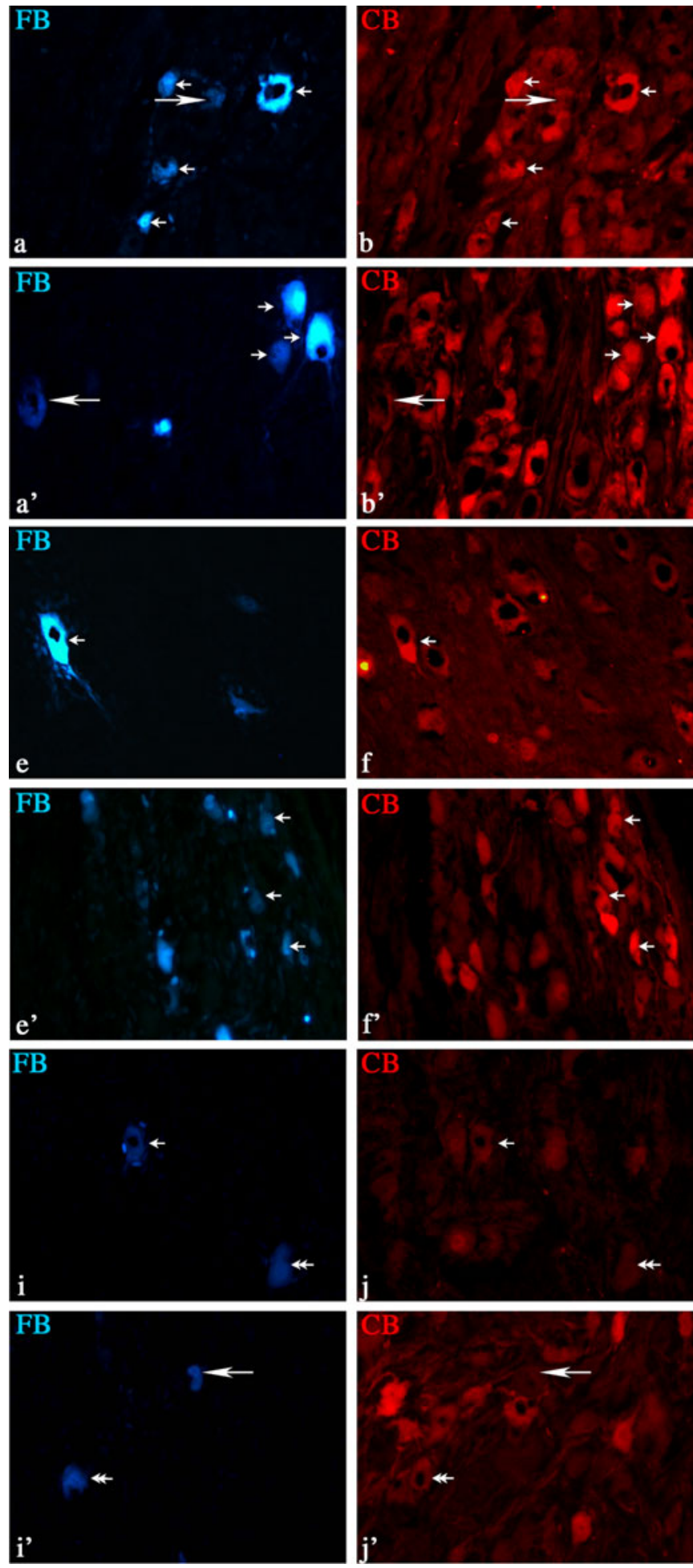

Fig. 1 Representative images of colon-projecting neurons located in IMG of the control animals $(\mathrm{C}, \mathrm{a}-\mathrm{l})$; and animals with $L$. intracellularis infection (PE, a'-l'). Figure parts d, d', h, h', 1, l' are composites of merged images taken separately from blue (a, a', e, e', i, and i'), red (b, b', f, f', j, and j') and green (c, c', g, g', k, k') fluorescent channels. Scale bar in each figure parts $=50 \mu \mathrm{m}$. a-d and $\mathbf{a}-\mathbf{d}^{\prime}-\mathrm{FB}^{+} / \mathrm{CB}^{+} / \mathrm{TH}^{+}$neurons in $\mathrm{C}$ and $\mathrm{PE}$ animals, respectively. Note the similar number of $\mathrm{FB}^{+}$(a and a') and $\mathrm{FB}^{+} / \mathrm{CB}^{+} / \mathrm{TH}^{+}$(d and $\mathrm{d}^{\prime}$ ) neurons in $\mathrm{C}$ and $\mathrm{PE}$ animals, respectively (small arrows). Some $\mathrm{FB}^{+}$neurons in both animal groups were $\mathrm{CB}$
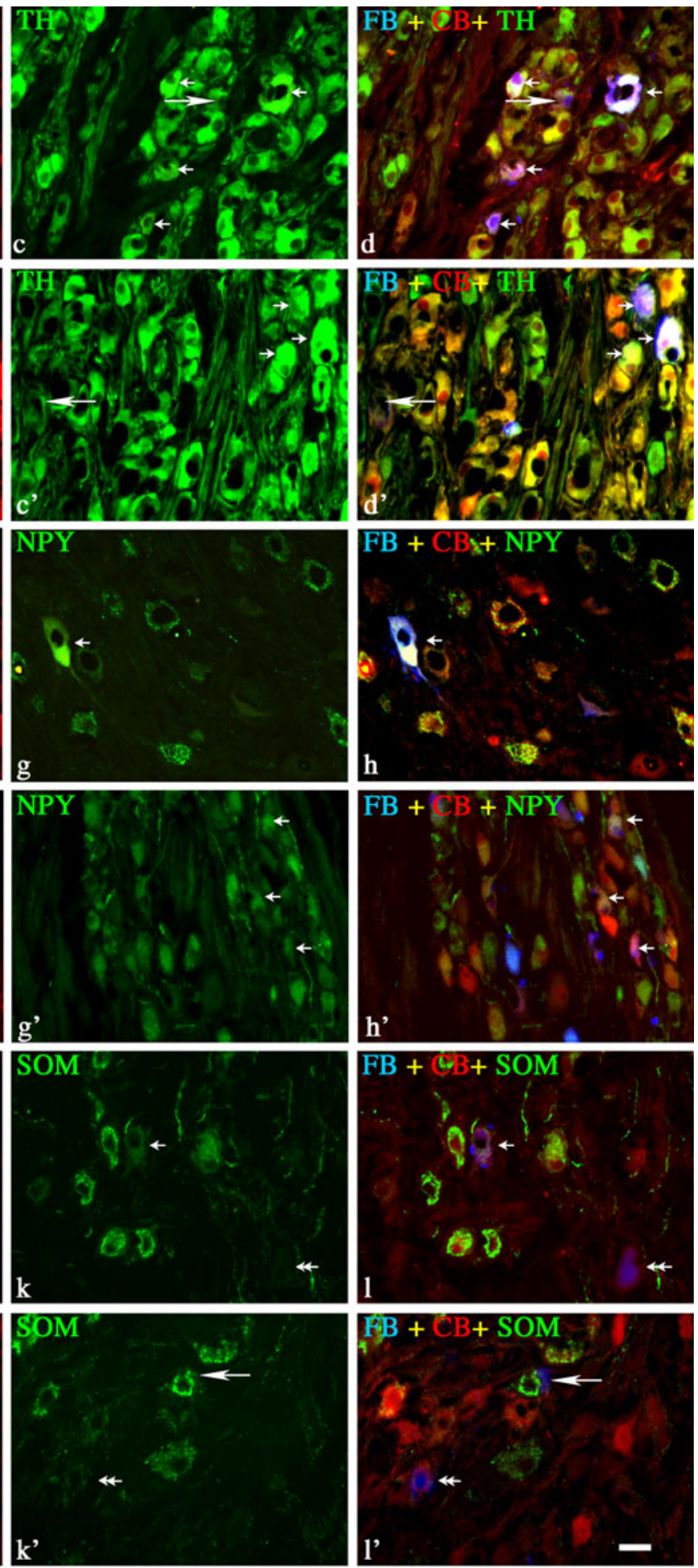

negative (long arrow). $\mathbf{e}-\mathbf{h}$ and $\mathbf{e}--\mathbf{h}--\mathrm{FB}^{+} / \mathrm{CB}^{+} / \mathrm{NPY}^{+}$neurons in $\mathrm{C}$ and $\mathrm{PE}$ animals, respectively. Note an increased number of $\mathrm{FB}^{+} / \mathrm{CB}^{+} /$ $\mathrm{NPY}^{+}\left(\mathrm{h}\right.$ and $\mathrm{h}$ ') neurons in $\mathrm{PE}$ animals (small arrows). $\mathrm{FB}^{+} / \mathrm{CB}^{+} /$ $\mathrm{NPY}^{+}$- small arrows, $\mathrm{FB}^{+} / \mathrm{CB}^{+} / \mathrm{NPY}^{-}$- double arrows, $\mathrm{FB}^{+} / \mathrm{CB}^{-} /$ $\mathrm{NPY}^{+}$- long arrows. i-l and $\mathbf{i}-\mathrm{l}^{\prime}-\mathrm{FB}^{+} / \mathrm{CB}^{+} / \mathrm{SOM}^{+}$neurons in $\mathrm{C}$ and $\mathrm{PE}$ animals, respectively. Note strong reduction in the number of $\mathrm{SOM}^{+}$ (k and $\mathrm{k}^{\prime}$ ) and $\mathrm{FB}^{+} / \mathrm{CB}^{+} / \mathrm{SOM}^{+}$(l and $\mathrm{l}^{\prime}$ ) neurons in $\mathrm{PE}$ animals (small arrows). $\mathrm{FB}^{+} / \mathrm{CB}^{+} / \mathrm{SOM}^{+}$- small arrows, $\mathrm{FB}^{+} / \mathrm{CB}^{+} / \mathrm{SOM}^{-}$-double arrows, $\mathrm{FB}^{+} / \mathrm{CB}^{-} / \mathrm{SOM}^{+}$- long arrows 


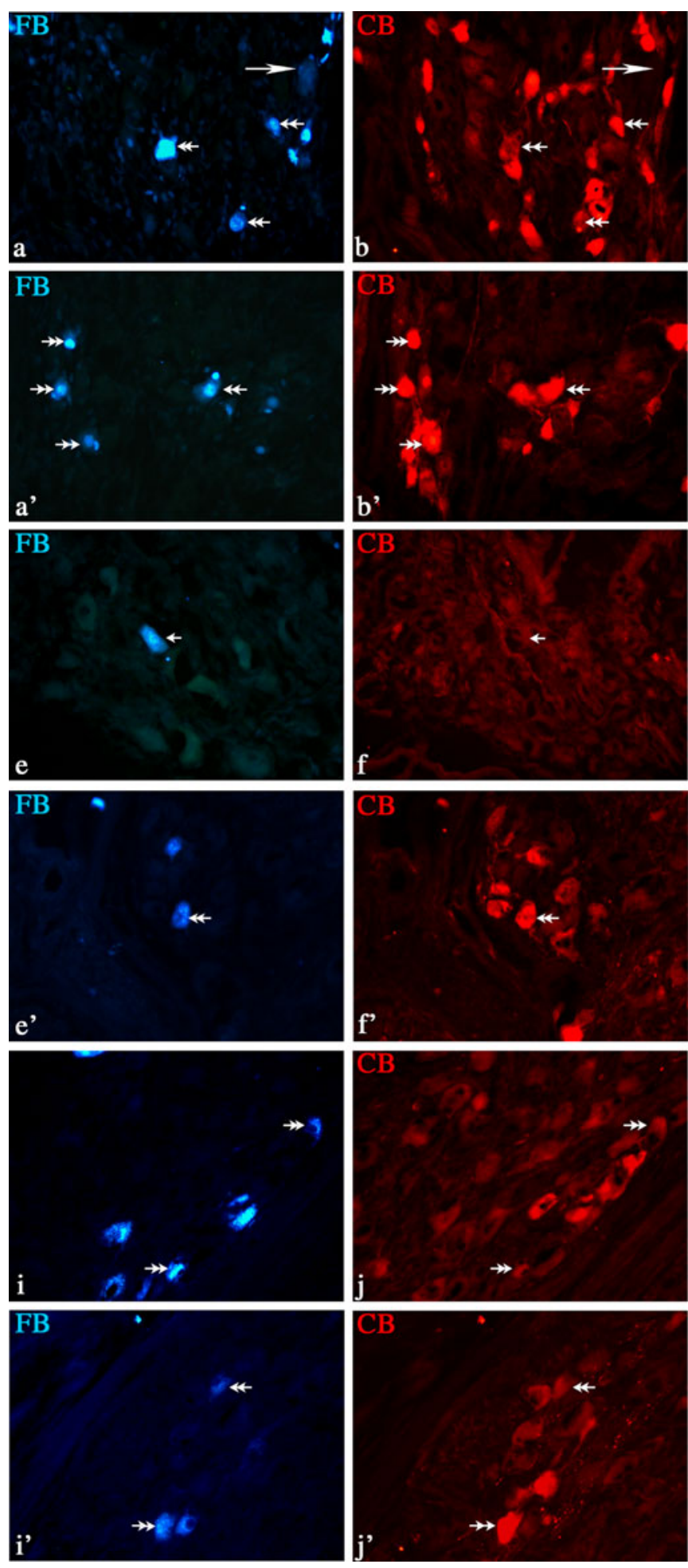

Fig. 2 Representative images of colon-projecting neurons located in IMG of the control animals $(\mathrm{C}, \mathrm{a}-1)$; and animals with $L$. intracellularis infection (PE, a'-l'). Figure parts d, d', h, h', 1, and l' are composites of merged images taken separately from blue (a, a', e, e', i, and i'), red (b, $b^{\prime}, f, f^{\prime}, j$, and j') and green (c, c', g, g', k, and k') fluorescent channels. Scale bar in each figure parts $=50 \mu \mathrm{m}$. a-d and $\mathbf{a}-\mathbf{d}^{\prime}-\mathrm{FB}^{+} / \mathrm{CB}^{+} / \mathrm{VIP}^{+}$ neurons in $\mathrm{C}$ and $\mathrm{PE}$ animals, respectively. $\mathrm{FB}^{+} / \mathrm{CB}^{+} / \mathrm{VIP}^{+}$- small
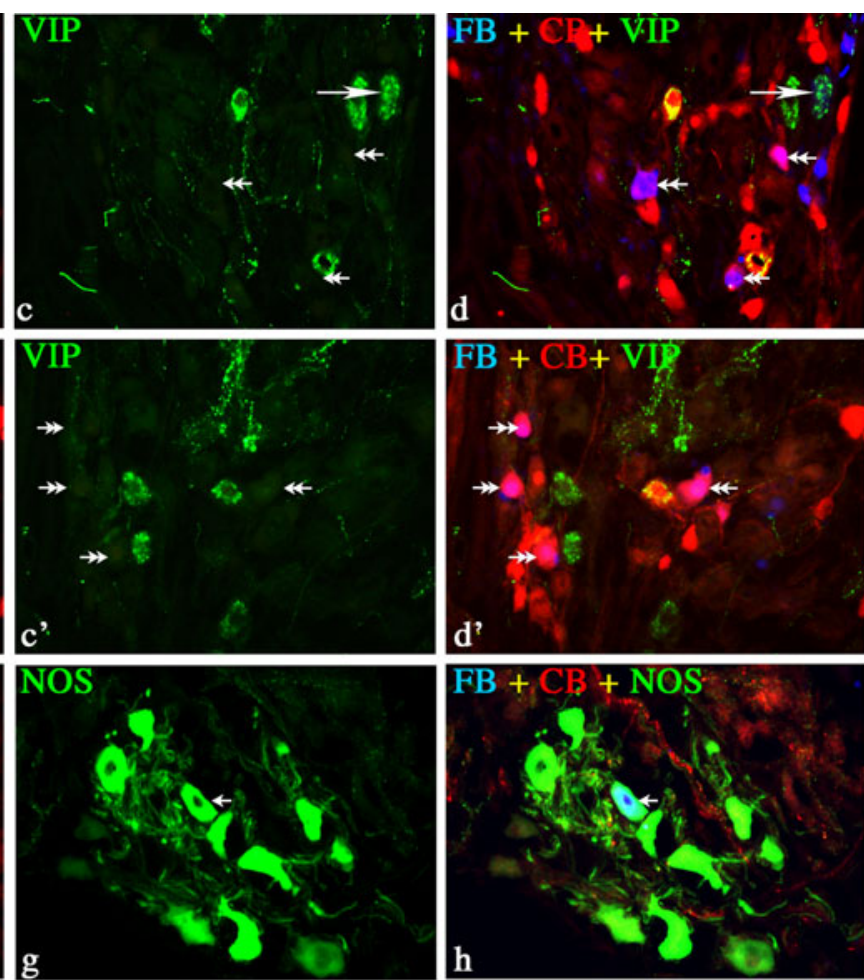

$\mathbf{d}^{\text {? }}$
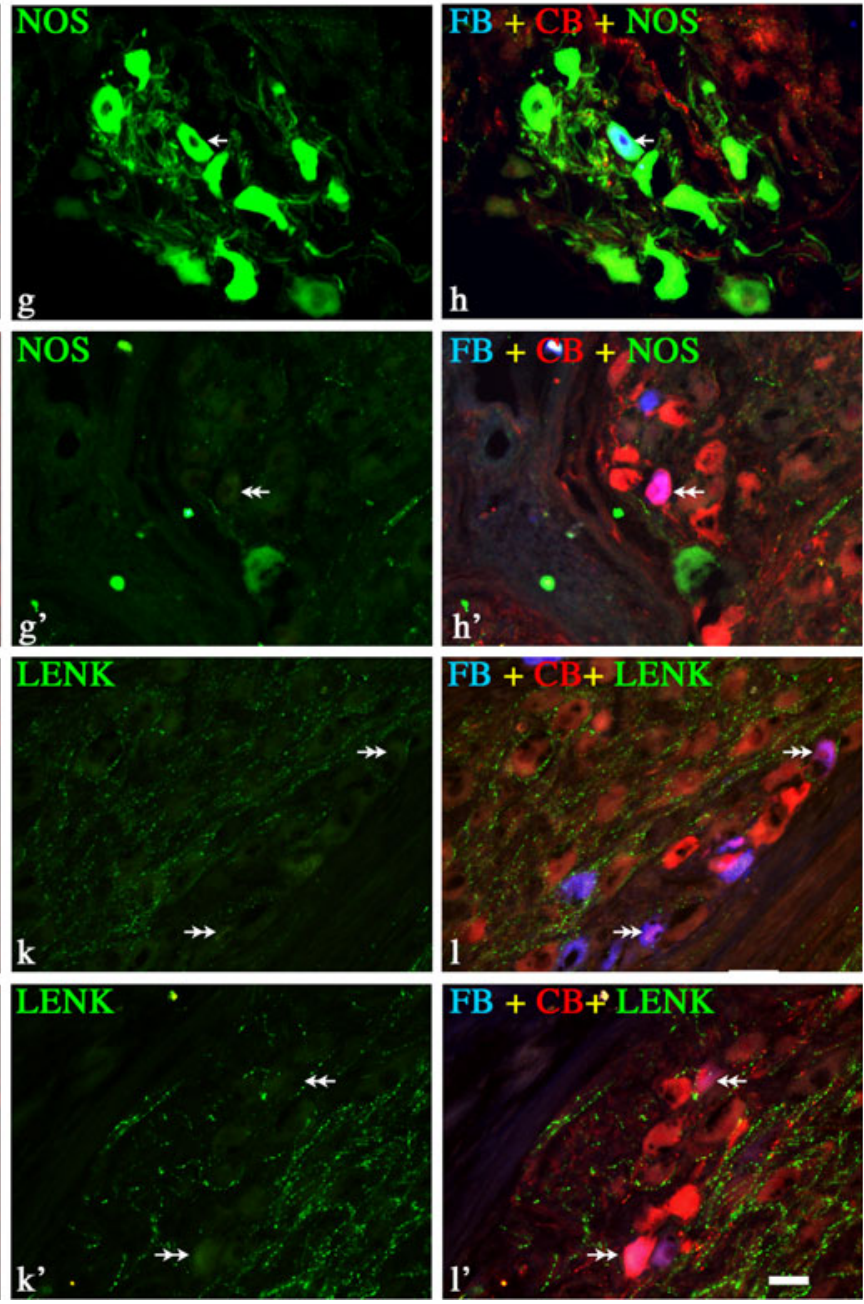

arrows, $\mathrm{FB}^{+} / \mathrm{CB}^{+} / \mathrm{VIP}^{-}$- double arrows. $\mathbf{e}-\mathbf{h}$ and $\mathbf{e}-\mathbf{h}$ '- note the lack of $\mathrm{FB}^{+} / \mathrm{CB}^{+} / \mathrm{NOS}^{+}$(h and $\mathrm{h}^{\prime}$ ) neurons in $\mathrm{C}$ and $\mathrm{PE}$ animals and strong reduction in the number of $\operatorname{NOS}^{+}$( $\mathrm{g}$ and $\mathrm{g}^{\prime}$ ) neurons in $\mathrm{PE}$ animals. $\mathrm{FB}^{+} / \mathrm{CB}^{+} / \mathrm{NOS}^{-}$- double arrows, $\mathrm{FB}^{+} / \mathrm{CB}^{-} / \mathrm{NOS}^{+}$- long arrows. i$\mathbf{l}$ and $\mathbf{i}-\mathbf{l}$ '- - note the lack of $\mathrm{FB}^{+} / \mathrm{CB}^{+} / \mathrm{LENK}^{+}\left(1\right.$ and $\left.\mathrm{l}^{\prime}\right)$ neurons in $\mathrm{C}$ and $\mathrm{PE}$ animals. $\mathrm{FB}^{+} / \mathrm{CB}^{+} / \mathrm{LENK}^{-}$- double arrows 
with Olympus CellSens image analyzing software (Olympus Japan). To determine the relative number of $\mathrm{FB} / \mathrm{CB}$-positive cells, the neurons were counted in every 16th section. Approximately $560 \mathrm{FB}^{+}$neurons were analyzed per animal. Cells devoid of $\mathrm{FB}^{+}$were not counted and only neurons with a clearly visible nucleus were scored. Data pooled from two different animals groups were expressed as means \pm standard error of mean (SEM) and were analyzed by using GraphPad Prism 5 software (GraphPad Software, La Jolla, CA, USA).

\section{Results}

The porcine IMG contained retrogradely labeled neurons projecting to the descending colon $\left(\mathrm{FB}^{+}\right)$; these were distributed bilaterally, i.e., within both left and the right ganglia. In each of these ganglia, $\mathrm{FB}^{+} / \mathrm{CB}^{+}$cells formed neurochemically heterogenous population composed of neurons using various substances as their main neurotransmitters (Figs. 1, 2, and 3 and Table 2). In animals with proliferative enteritis, the size of the whole population of $\mathrm{FB}^{+}$neurons did not change; however, the coding patterns of many $\mathrm{FB}^{+} / \mathrm{CB}^{+}$cells were changed (Figs. 1, 2 and 3 and Table 2).

In control animals, FB/CB-positive neurons supplying the colon formed a morphologically and neurochemically heterogeneous population of neurons (Fig. 1, 2, and 3 and Table 2). The majority of these neurons were immunoreactive for tyrosine hydroxylase and neuropeptide Y (Fig. 1a$\mathrm{h}$ and Table 2). Another large subpopulation of $\mathrm{FB}^{+} / \mathrm{CB}^{+}$ neurons were those containing SOM. These cells constituted almost $37 \%$ of $\mathrm{FB}^{+} / \mathrm{CB}^{+}$neurons (Fig. $1 \mathrm{i}-1$ and Table 2). A small subpopulations of $\mathrm{FB} / \mathrm{CB}$-positive neurons coexpressed vasoactive intestinal peptide (3\%; Fig. 2a-d and Table 2). In the animals with clinically diagnosed $L$. intracellularis infection, the numbers of $\mathrm{FB} / \mathrm{CB} / \mathrm{TH}$-positive neurons did not change (Figs. 1a'-d' and 3 and Table 2). On the other hand, a subpopulation of $\mathrm{FB}^{+} / \mathrm{CB}^{+} / \mathrm{NPY}^{+}$cells increased more than $13 \%$ (Figs. 1 e'-h' and 3 and Table 2). The number of $\mathrm{FB}^{+} / \mathrm{CB}^{+} / \mathrm{SOM}^{+}$cells was reduced by more
Table 2 Relative frequencies of the main subsets of $\mathrm{CB}^{+} / \mathrm{FB}^{+}$neurons in the inferior mesenteric ganglia of control and $\mathrm{PE}$ animals

\begin{tabular}{lll}
\hline & $\mathrm{FB}^{+} / \mathrm{CB}^{+} / \mathrm{P}^{+}$ & \\
\cline { 2 - 3 } & $\mathrm{C}$ & $\mathrm{PE}$ \\
\hline $\mathrm{TH}$ & $93.0 \pm 2.4$ & $93.0 \pm 1.4$ \\
NPY & $72.1 \pm 3.2$ & $82.3 \pm 2.3$ \\
SOM & $36.9 \pm 3.5$ & $16.4 \pm 1.1$ \\
VIP & $3.2 \pm 0.8$ & 0 \\
NOS & 0 & 0 \\
LENK & 0 & 0 \\
SP & 0 & 0 \\
VAChT & 0 & 0 \\
GAL & 0 & 0 \\
PACAP & 0 & 0 \\
\hline
\end{tabular}

P stands for "peptide" (e.g., NPY, SOM, VIP etc.)

than $60 \%$ and $\mathrm{FB}^{+} / \mathrm{CB}^{+} / \mathrm{VIP}^{+}$cells were not observed (Figs. 1i'- $\mathrm{l}^{\prime}, 2 \mathrm{a}^{\prime}-\mathrm{d}^{\prime}$, and 3 and Table 2).

None of the FB/CB-positive perikarya was immunopositive to NOS, LENK, SP, VAChT, GAL, and PACAP (Figs. 2e$1,2 e^{\prime}-1$ ', and 3 and Table 2) in both experimental groups.

\section{Discussion}

The results of the present study indicate that although proliferative enteropathy had no influence on the number of CBpositive, colon-projecting IMG neurons, it had a large impact on their chemical coding pattern. For example, while $\mathrm{CB} / \mathrm{TH}-$ expressing neurons were unaffected in the IMG of animals with proliferative enteropathy, CB/NPY-expressing neurons increased in number, and the numbers of $\mathrm{CB}$ neurons immunoreactive to SOM or VIP were reduced. Changes in chemical coding of $\mathrm{CB}$ neurons during proliferative enteropathy may play an important role in the adaptation of these IMG cells under pathological conditions.

The present study demonstrates that $\mathrm{CB} / \mathrm{TH}$-expressing neurons were unaffected in IMG of animals with proliferative
Fig. 3 Diagram illustrating the $\mathrm{FB}^{+} / \mathrm{CB}^{+}$cell numbers which were immunoreactive to appropriate antigens in IMGs of control (light grey bars) and PE animals (dark grey bars) (in percent). Student's $t$ test, $* * * P \leq 0.001, * * P \leq 0.01$,

$* P \leq 0.05$

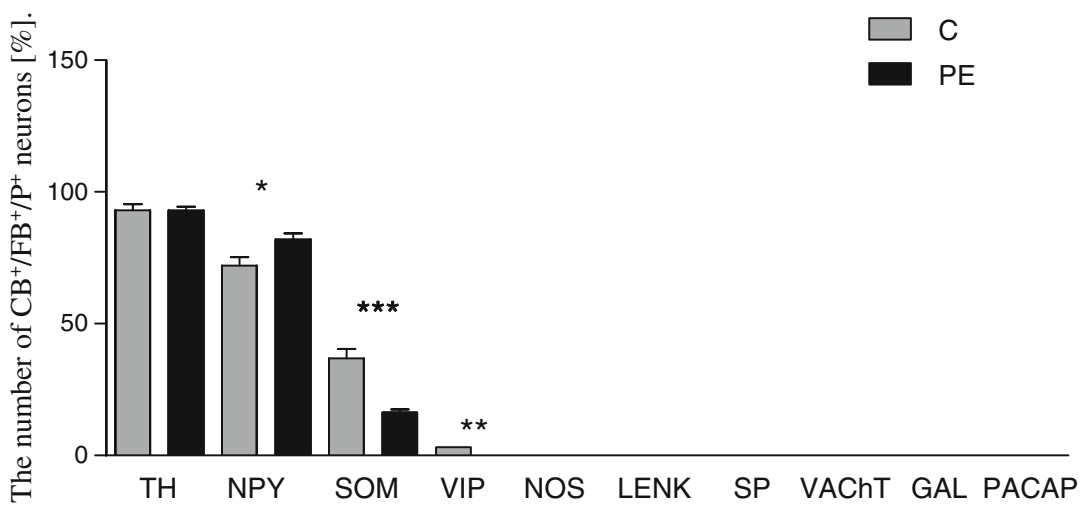


enteropathy. $\mathrm{CB} / \mathrm{TH}$ colon-projecting IMG neurons innervate the myenteric and submucous ganglia and the muscle layers, predominantly in the longitudinal muscle ( $\mathrm{Li}$ and Masuko 1997). These neurons are considered to be visceromotor neurons because the terminals of these neurons surround neurons of the enteric plexuses (Parr and Sharkey 1996). They are thought to modulate or inhibit colon motility because their fibers and terminals are found around myenteric ganglion neurons which are essential for enteric reflex motor activity. For example, $\mathrm{TH}^{+}$terminals form basket-like endings around cholinergic motor neurons and 5-HT-handling neurons (Gershon and Sherman 1982, 1987; Tassicker et al. 1999). Noradrenaline acts presynaptically to inhibit release of neurotransmitters in the myenteric plexus (Furness et al. 1990; Manber and Gershon 1979; Paton and Vizi 1969; Tassicker et al. 1999), but noradrenaline does not hyperpolarize myenteric neurons directly (Manber and Gershon 1979; Nishi and North 1973).

The present study also demonstrates that CB/NPYexpressing neurons increased in number in the IMG of animals with proliferative enteropathy. The number of NPY neurons is usually elevated in various other enteric diseases (Czaja et al. 2005; Lakomy et al. 2005; Majewski et al. 2004). For example, experiments that examined the influence of colitis on the chemical coding of porcine prevertebral neurons revealed an increase in the number of NPY neurons (Majewski et al. 2004). The numbers of enteric intramural NPY neurons are also elevated in the intestines of pigs with experimental ileitis (Czaja et al. 2005). Similarly, in animals with porcine dysentery, NPY expression has been reported to be elevated in the IMG (Lakomy et al. 2005). NPY has been implicated as mediator involved in the pathogenesis of numerous gastrointestinal disorders, including malabsorption, short gut, inflammatory bowel disease, and various forms of pancreatitis (Vona-Davis and McFadden 2007). However, the exact physiological role of NPY in all these pathologies is not yet clear and requires further investigation. In normal conditions NPYcontaining neurons of the IMG were considered vasomotor neurons because their fibers and terminals surrounded arterial vessels in the colon wall (Costa and Furness 1984; Lundberg et al. 1982), thus, influencing their control on arterial blood flow though the colon wall.

The results of the present study also indicate that the numbers of CB neurons immunoreactive to SOM or VIP were reduced in IMG of animals with proliferative enteropathy. SOM is considered to be anti-inflammatory and antinociceptive factor which may be actively involved in the pathophysiological inflammation of the intestines and possibly in other organs as well (Reubi et al. 1994). Some of the postulated SOM actions include the reduction of inflammatory nociception, nociceptor excitation, and sensitization (Abd ElAleem et al. 2005; Hasler et al. 1993; Pinter et al. 2006;
Plourde et al. 1993). Moreover, SOM seems to play an important role not only in neurotransmission but also in the immune response to inflammation. For example, there is evidence that SOM downregulates the expression and release of proinflammatory cytokines (Blum et al. 1992; Chowers et al. 2000) through the modulation of lymphocyte proliferation (Stanisz et al. 1986) and immunoglobulin production (ten Bokum et al. 2000; Blum et al. 1992). The number of VIPexpressing neurons was reduced to undetectable levels in the IMG of animals with PE. As VIP is also widely accepted as an anti-inflammatory factor (Abad et al. 2003; Delgado and Ganea 2001; Delgado et al. 2002), an increase of the number of VIP-expressing cells could be expected, and previous studies have reported an elevation of VIP neurons in the intramural ganglia of animals afflicted with PE (Pidsudko et al. 2008). The literature concerning the influence of pathological conditions on VIP-expressing neurons is incomplete and sometimes contradictory. For example, in animals with experimental Schistosoma japonicum-induced colitis, VIP immunoreactivity was markedly reduced in the intramural neurons (Balemba et al. 1998). Moreover, in the most severely damaged regions of the intestine, the expression of this neuropeptide was undetectable (Balemba et al. 1998). Conversely, VIP expression was elevated in the IMG of animals with swine dysentery (Lakomy et al. 2005). However, it is important to note that in normal conditions, SOM and VIP cells of the IMG in cooperation with $\mathrm{TH}$ are involved in controlling and modulating the motility and glandular secretion of the colon (Costa and Furness 1984; Gershon and Sherman 1982, 1987; Lundberg et al. 1982; Tassicker et al. 1999).

In conclusion, the results of the present study indicate that colon-projecting IMG neurons that express $\mathrm{CB}$ are affected in animals with PE. The number of $\mathrm{CB}$ neurons expressing NPY was upregulated, while the numbers of $\mathrm{CB}$ neurons expressing SOM and VIP were distinctly reduced. These changes in the chemical coding of IMG neurons observed under pathological condition investigated in this study indicate adaptive mechanism(s) of the IMG neurons, promoting their survival and/or regeneration.

Open Access This article is distributed under the terms of the Creative Commons Attribution Noncommercial License which permits any noncommercial use, distribution, and reproduction in any medium, provided the original author(s) and source are credited.

\section{References}

Abad C, Martinez C, Juarranz MG, Arranz A, Leceta J, Delgado M, Gomariz RP (2003) Therapeutic effects of vasoactive intestinal peptide in the trinitrobenzene sulfonic acid mice model of Crohn's disease. Gastroenterology 124:961-971 
Abd El-Aleem SA, Morales-Aza BM, McQueen DS, Donaldson LF (2005) Inflammation alters somatostatin mRNA expression in sensory neurons in the rat. Eur J Neurosci 21:135-141

Balemba OB, Grondahl ML, Mbassa GK, Semuguruka WD, HaySmith A, Skadhauge E, Dantzer V (1998) The organisation of the enteric nervous system in the submucous and mucous layers of the small intestine of the pig studied by VIP and neurofilament protein immunohistochemistry. J Anat 192:257-267

Bastianelli E (2003) Distribution of calcium-binding proteins in the cerebellum. Cerebellum 2:242-262

Biasi F, Astegiano M, Maina M, Leonarduzzi G, Poli G (2011) Polyphenol supplementation as a complementary medicinal approach to treating inflammatory bowel disease. Curr Med Chem Sep. 15

Blum AM, Metwali A, Mathew RC, Cook G, Elliott D, Weinstock JV (1992) Granuloma T lymphocytes in murine schistosomiasis mansoni have somatostatin receptors and respond to somatostatin with decreased IFN-gamma secretion. J Immunol 149:3621-3626

Brown DR, Timmermans JP (2004) Lessons from the porcine enteric nervous system. Neurogastroenterol Motil 16:50-54

Cho YJ, Lee JC, Kang BG, An J, Song HS, Son O, Nam DH, Cha CI, Joo KM (2011) Immunohistochemical study on the expression of calcium binding proteins (calbindin-D28k, calretinin, and parvalbumin) in the cerebral cortex and in the hippocampal region of nNOS knock-out(-/-) mice. Anat Cell Biol 44:106-115

Chowers Y, Cahalon L, Lahav M, Schor H, Tal R, Bar-Meir S, Levite M (2000) Somatostatin through its specific receptor inhibits spontaneous and TNF-alpha- and bacteria-induced IL- 8 and IL-1 beta secretion from intestinal epithelial cells. J Immunol 165:2955-2961

Costa M, Furness JB (1984) Somatostatin is present in a subpopulation of noradrenergic nerve fibres supplying the intestine. Neuroscience 13:911-919

Czaja K, Kaleczyc J, Sienkiewicz W, Lakomy M (2005) The influence of experimental ileitis on the neuropeptide coding of enteric neurons in the pig. Pol J Vet Sci 8:155-163

Dalsgaard CJ, Elfvin LG (1982) Structural studies on the connectivity of the inferior mesenteric ganglion of the guinea pig. J Auton Nerv Syst 5:265-278

Delgado M, Ganea D (2001) Inhibition of endotoxin-induced macrophage chemokine production by vasoactive intestinal peptide and pituitary adenylate cyclase-activating polypeptide in vitro and in vivo. J Immunol 167:966-975

Delgado M, Abad C, Martinez C, Juarranz MG, Arranz A, Gomariz RP, Leceta J (2002) Vasoactive intestinal peptide in the immune system: potential therapeutic role in inflammatory and autoimmune diseases. J Mol Med 80:16-24

Ekblad E (1999) Pharmacological evidence for both neuronal and smooth muscular PAC1 receptors and a VIP-specific receptor in rat colon. Regul Pept 85:87-92

Elson CO, Sartor RB, Tennyson GS, Riddell RH (1995) Experimental models of inflammatory bowel disease. Gastroenterology 109:1344-1367

Furness JB (2000) Types of neurons in the enteric nervous system. J Auton Nerv Syst 81:87-96

Furness JB, Kuramoto H, Messenger JP (1990) Morphological and chemical identification of neurons that project from the colon to the inferior mesenteric ganglia in the guinea-pig. J Auton Nerv Syst 31:203-210

Gershon MD, Sherman DL (1982) Identification of and interactions between noradrenergic and serotonergic neurites in the myenteric plexus. J Comp Neurol 204:407-421

Gershon MD, Sherman DL (1987) Noradrenergic innervation of serotoninergic neurons in the myenteric plexus. J Comp Neurol 259:193-210

Gonkowski S, Calka J (2010) Changes in the somatostatin (SOM)-like immunoreactivity within nervous structures of the porcine descending colon under various pathological factors. Exp Mol Pathol 88:416-423

Hasler WL, Soudah HC, Owyang C (1993) A somatostatin analogue inhibits afferent pathways mediating perception of rectal distention. Gastroenterology 104:1390-1397

Lakomy M, Sienkiewicz W, Zmudzki J, Wasowicz K (2005) Changes in the expression of some neuropeptide in the intestines and nerve ganglia during the porcine dysyntery. Bull Vet Inst Pulawy 49:393-398

Lawson GH, Gebhart CJ (2000) Proliferative enteropathy. J Comp Pathol 122:77-100

Lawson GH, McOrist S, Jasni S, Mackie RA (1993) Intracellular bacteria of porcine proliferative enteropathy: cultivation and maintenance in vitro. J Clin Microbiol 31:1136-1142

Li MZ, Masuko S (1997) Neuronal circuitry between the inferior mesenteric ganglion and lower intestine of the dog. Arch Histol Cytol 60:391-404

Li MZ, Masuko S (2001) Target specific organization and neuron types of the dog pelvic ganglia: a retrograde-tracing and immunohistochemical study. Arch Histol Cytol 64:267-280

Luckensmeyer GB, Keast JR (1994) Projections from the prevertebral and major pelvic ganglia to the ileum and large intestine of the male rat. J Auton Nerv Syst 49:247-259

Lundberg JM, Terenius L, Hokfelt T, Martling CR, Tatemoto K, Mutt V, Polak J, Bloom S, Goldstein M (1982) Neuropeptide Y (NPY)-like immunoreactivity in peripheral noradrenergic neurons and effects of NPY on sympathetic function. Acta Physiol Scand 116:477-480

Majewski M, Wojtkiewicz J, Gonkowski S, Bossowska A, Sienkiewicz W, Kaleczyc J (2004) Proliferative enterophaty (PE)-induced changes in the expression pattern of DBH, NPY and/or SOM in porcine IMG neurons supplying the descending colon. Pol J Vet Sci 7:77-79

Manber L, Gershon MD (1979) A reciprocal adrenergic-cholinergic axoaxonic synapse in the mammalian gut. Am J Physiol 236: E738-E745

McOrist S, Lawson GH (1993) Porcine proliferative enteropathy. Vet Rec 132:368

Nishi S, North RA (1973) Presynaptic action of noradrenaline in the myenteric plexus. J Physiol 231:29P-30P

Paton WD, Vizi ES (1969) The inhibitory action of noradrenaline and adrenaline on acetylcholine output by guinea-pig ileum longitudinal muscle strip. Br J Pharmacol 35:10-28

Parr EJ, Sharkey KA (1996) Immunohistochemically-defined subtypes of neurons in the inferior mesenteric ganglion of the guinea-pig. J Auton Nerv Syst 59:140-150

Phillips RJ, Powley TL (2007) Innervation of the gastrointestinal tract: patterns of aging. Auton Neurosci 136:1-19

Pidsudko Z, Kaleczyc J, Majewski M, Lakomy M, Scheuermann DW, Timmermans JP (2001) Differences in the distribution and chemical coding between neurons in the inferior mesenteric ganglion supplying the colon and rectum in the pig. Cell Tissue Res 303:147-158

Pidsudko Z, Kaleczyc J, Wasowicz K, Sienkiewicz W, Majewski M, Zajac W, Lakomy M (2008) Distribution and chemical coding of intramural neurons in the porcine ileum during proliferative enteropathy. J Comp Pathol 138:23-31

Pinter E, Helyes Z, Szolcsanyi J (2006) Inhibitory effect of somatostatin on inflammation and nociception. Pharmacol Ther 112:440-456

Plourde V, Lembo T, Shui Z, Parker J, Mertz H, Tache Y, Sytnik B, Mayer E (1993) Effects of the somatostatin analogue octreotide on rectal afferent nerves in humans. Am J Physiol 265:G742-G751

Resibois A, Vienne G, Pochet R (1988) Calbindin-D28K and the peptidergic neuroendocrine system in rat gut: an immunohistochemical study. Biol Cell 63:67-75

Reubi JC, Mazzucchelli L, Laissue JA (1994) Intestinal vessels express a high density of somatostatin receptors in human inflammatory bowel disease. Gastroenterology 106:951-959 
Smith DG, Lawson GH (2001) Lawsonia intracellularis: getting inside the pathogenesis of proliferative enteropathy. Vet Microbiol $82: 331-345$

Stanisz AM, Befus D, Bienenstock J (1986) Differential effects of vasoactive intestinal peptide, substance $P$, and somatostatin on immunoglobulin synthesis and proliferations by lymphocytes from Peyer's patches, mesenteric lymph nodes, and spleen. J Immunol 136:152-156

Tassicker BC, Hennig GW, Costa M, Brookes SJ (1999) Rapid anterograde and retrograde tracing from mesenteric nerve trunks to the guinea-pig small intestine in vitro. Cell Tissue Res 295:437-452

Ten Bokum AM, Hofland LJ, van Hagen PM (2000) Somatostatin and somatostatin receptors in the immune system: a review. Eur Cytokine Netw 11:161-176

Trudrung P, Furness JB, Pompolo S, Messenger JP (1994) Locations and chemistries of sympathetic nerve cells that project to the gastrointestinal tract and spleen. Arch Histol Cytol $57: 139-150$
Vasina V, Barbara G, Talamonti L, Stanghellini V, Corinaldesi R, Tonini M, De PF, De GR (2006) Enteric neuroplasticity evoked by inflammation. Auton Neurosci 126-127:264-272

Vona-Davis LC, McFadden DW (2007) NPY family of hormones: clinical relevance and potential use in gastrointestinal disease. Curr Top Med Chem 7:1710-1720

Wasserman RH, Taylor AN, Kallfelz FA (1966) Vitamin D and transfer of plasma calcium to intestinal lumen in chicks and rats. Am J Physiol 211:419-423

Wojtkiewicz J, Gonkowski S, Bossowska A, Kaleczyc J, Majewski M (2004) Proliferative enterophaty (PE)-induced changes in the distribution pattern of vesicular acetylcholine transporter-immunoreactive (VAChT-IR) nerve terminal in the porcine inferior mesenteric ganglion (IMG). Polish J Vet Sci 7:156-161

Wojtkiewicz J, Rowniak M, Crayton R, Barczewska M, Bladowski M, Robak A, Pidsudko Z, Majewski M (2011) Inflammation-induced changes in the chemical coding pattern of colon-projecting neurons in the inferior mesenteric ganglia of the pig. J Mol Neurosci. doi:10.1007/s12031-011-9613-4: 